\title{
Suppressive effect of an aqueous extract of Diospyros kaki calyx on dust mite extract/2,4-dinitrochlorobenzene-induced atopic dermatitis-like skin lesions
}

\author{
JU-HEE YU ${ }^{1 *}$, MEILING JIN ${ }^{1 *}$, YOUNG-AE CHOI ${ }^{*}$, NA-HEE JEONG ${ }^{1}$, \\ JEONG-SOOK PARK ${ }^{2}$, TAE-YONG SHIN ${ }^{3}$ and SANG-HYUN KIM ${ }^{1}$
}

${ }^{1}$ CMRI, Department of Pharmacology, School of Medicine, Kyungpook National University, Daegu 700-422; ${ }^{2}$ Department of Nursing, Nambu University, Gwangju 506-706;

${ }^{3}$ College of Pharmacy, Woosuk University, Jeonju 565-701, Republic of Korea

Received October 25, 2016; Accepted June 1, 2017

DOI: $10.3892 / \mathrm{ijmm} .2017 .3017$

\begin{abstract}
Atopic dermatitis (AD) is a common chronic inflammatory skin disease, affecting $10-20 \%$ of individuals worldwide. Therefore, the discovery of drugs for treating $\mathrm{AD}$ is an attractive subject and important to human health. Diospyros kaki and Diospyros kaki (D. kaki) folium exert beneficial effects on allergic inflammation. However, the effect of $D$. kaki calyx on AD remains elusive. The present study evaluated the effects of an aqueous extract of $D$. kaki calyx (AEDKC) on AD-like skin lesions using mouse and keratinocyte models. We used a mouse AD model by the repeated skin exposure of house dust mite extract [Dermatophagoides farinae extract (DFE)] and 2,4-dinitrochlorobenzene (DNCB) to the ears. In addition, to determine the underlying mechanism of its operation, tumor necrosis factor- $\alpha$ (TNF- $\alpha$ ) and interferon- $\gamma($ IFN- $\gamma)$-activated keratinocytes (HaCaT) were used. Oral administration of AEDKC decreased AD-like skin lesions, as demonstrated by the reduced ear thickness, serum immunoglobulin E (IgE), DFE-specific IgE, IgG2a, histamine level and inflammatory cell infiltration. AEDKC inhibited the expression of pro-inflammatory cytokines and a chemokine via downregulation of nuclear factor- $\kappa \mathrm{B}$ and signal transducer and activator of transcription 1 in $\mathrm{HaCaT}$ cells. On examination of the AD-related factors in vivo and in vitro, it was confirmed that AEDKC decreased AD-like skin lesions. Taken together,
\end{abstract}

Correspondence to: Professor Sang-Hyun Kim, CMRI, Department of Pharmacology, School of Medicine, Kyungpook National University, 2-101 Dongin-dong, Jung-gu, Daegu 700-422, Republic of Korea E-mail: shkim72@knu.ac.kr

Professor Tae-Yong Shin, College of Pharmacy, Woosuk University, Jeonju 565-701, Republic of Korea

E-mail: tyshin@woosuk.ac.kr

*Contributed equally

Key words: Diospyros kaki calyx, atopic dermatitis, keratinocytes, house dust mite, histamine the results suggest that AEDKC is a potential drug candidate for the treatment of AD.

\section{Introduction}

Atopic dermatitis (AD) is a chronic allergic inflammatory skin disease, characterized by pruritic, skin thickening, erythema, and eczematous skin lesions (1). The interaction of multiple factors such as environmental factors, skin barrier function, and the immune system is attributed to the pathogenesis of AD (2). Among the environmental factors, Dermatophagoides farinae (D. farinae) is a type of house dust mite and is a common environmental allergen associated with human AD. D. farinae extract (DFE) is known to contribute to the pathogenesis of AD by inducing both acute and chronic AD lesions (3-5). The major mechanistic studies on AD point to the imbalance of Th1 and Th2 responses in favor of Th2 responses $(4,6)$. Other studies have reported that the acute and chronic phases of AD are predominantly a Th2 and Th1 response, respectively $(1,7,8)$. It is also known that immunoglobulin $\mathrm{E}(\mathrm{IgE})$ production is associated with Th2 cellular response, whereas IgG2a is associated with Th1 response (1). The importance of Th1 and Th2 cytokines in skin inflammation has been demonstrated $(4,9)$. The major cytokines released from Th1 and Th 2 cells are interferon- $\gamma($ IFN- $\gamma$ ) and interleukin-4 (IL-4) (10). IL-4 and IFN- $\gamma$ play critical roles in isotype switching to $\operatorname{IgE}$ and $\operatorname{IgG} 2 \mathrm{a}$, respectively (1).

Keratinocyte activation is a feature of the pathogenesis of the acute and chronic stages of AD (11). The keratinocytes of AD patients exhibit a propensity for an exaggerated cytokine/chemokine expression, a phenomenon that may be relevant in promoting and maintaining inflammation (12). Therefore, the suppression of keratinocyte activation is a target for the treatment of AD (13).

The treatment of AD mainly consists of topical steroid creams and oral steroids as immunosuppressants (14). However, chronic usage of steroids can cause thinning of the skin, leading to cracking and bleeding (15). Hence, drugs with no side effects for the treatment of AD are still being extensively explored. Recently, many natural products have been reported 
to exhibit anti-inflammatory properties and have the potential to treat skin inflammatory disorders, especially $\operatorname{AD}(16,17)$.

Diospyros kaki (Ebenaceae) is a well-known conventional medicinal herb (18). D. kaki calyx is also generally used as a traditional medicine in Asia to relieve asthma, chronic bronchitis, and cough symptoms (19,20). D. kaki calyx contains various biologically active compounds, such as stearic acid, palmitic acid, succinic acid, syringic acid, vanillic acid, gallic acid, kaempferol, trifolin, $\beta$-hydroxyursolic acid, friedelin, oleanolic acid, quercetin, $\beta$-sitosterol and ursolic acid (21). Among the various compounds, gallic acid, quercetin, $\beta$-sitosterol and oleanolic acid are already known to possess anti-AD potential (4,22-24). In spite of various studies regarding the biological effects of $D$. kaki, the anti-AD effect of $D$. kaki calyx has not yet been reported. The aim of the present study was to assure the beneficial effects of aqueous extract of D. kaki calyx (AEDKC) on AD and to define the underlying mechanisms of these effects.

\section{Materials and methods}

Animals. Six-week-old female BALB/c mice were purchased from SLC Inc. (Hamamatsu, Japan). The mice were housed with 5 mice/cage in a laminar air flow room maintained at a temperature of $22 \pm 2^{\circ} \mathrm{C}$, a relative humidity of $55 \pm 5 \%$ and a $12 \mathrm{~h}$ light:dark cycle throughout the study. The care and treatment of the mice were in accordance with the guidelines established by the Public Health Service Policy on the Humane Care and Use of Laboratory Animals and were approved by the Institutional Animal Care and Use Committee of Kyungpook National University.

Preparation of AEDKC, reagents and cell culture. D. kaki calyx used in this study was purchased from the Oriental drug store Bohwa Dang (Jeonju, Korea) and identified by Dr D.K. Kim at the College of Pharmacy, Woosuk University. A voucher specimen (no. WSP-15-098) was deposited at the Herbarium of the College of Pharmacy, Woosuk University. The sample was extracted with purified water at $70^{\circ} \mathrm{C}$ for $5 \mathrm{~h}$ (2 times) in a water bath. Then the extract was filtered, lyophilized, and then kept at $4^{\circ} \mathrm{C}$. The yield of dried extract from starting crude materials was $\sim 10.1 \%$.

For the animal experiments, the dried residue was dissolved in phosphate-buffered saline (PBS). DFE (Greer Laboratories, Lenoir, NC, USA) and 2,4-dinitrochlorobenzene (DNCB) were used as antigen and hapten for the induction of AD-like skin lesions, respectively. All other reagents were purchased from Sigma (St. Louis, MO, USA) unless otherwise stated. DFE was dissolved in PBS containing 0.5\% Tween-20. DNCB was dissolved in an acetone/olive oil (1:3) solution. Recombinant human tumor necrosis factor- $\alpha(\mathrm{TNF}-\alpha)$ and IFN- $\gamma$ were purchased from R\&D Systems (Minneapolis, MN, USA).

A human keratinocyte cell line, $\mathrm{HaCaT}$, was maintained in Dulbecco's modified Eagle's medium (DMEM) supplemented with $10 \%$ fetal bovine serum (FBS) and antibiotics $(100 \mathrm{U} / \mathrm{m}$ penicillin $\mathrm{G}, 100 \mu \mathrm{g} / \mathrm{ml}$ streptomycin) at $37^{\circ} \mathrm{C}$ under $5 \% \mathrm{CO}_{2}$. Passages 3-6 were used throughout the study.

Induction of $A D$-like lesions in the ears of mice. AD-like lesions were induced by DFE and DNCB according to previous studies $(4,5)$. The schematic experimental procedure is described in Fig. 1A. Female BALB/c mice were divided into 6 groups $(n=5)$ : vehicle, DFE/DNCB plus vehicle, DFE/DNCB plus AEDKC (1, 10 and $100 \mathrm{mg} / \mathrm{kg}$ ), or dexamethasone (Dexa, $1 \mathrm{mg} / \mathrm{kg}$ ). Mice were anesthetized with ketamine and the surfaces of both ear lobes were very gently stripped 4 times with surgical tape (Nichiban, Tokyo, Japan). Then, $20 \mu \mathrm{l}$ of DNCB (1\%) was painted on each ear and then with $20 \mu \mathrm{l}$ of DFE (10 mg/ml) 4 days later. DFE/DNCB exposure was repeated once a week rotationally for 4 weeks. Two weeks after the first induction, tail bleeding was performed to evaluate the serum IgE level. After the confirmation of AD, as indicated by the IgE level, AEDKC was orally administered until the end of the 4-week induction (5 times/week). Ear thickness was measured the following day at the same time after DFE or DNCB application using a dial thickness gauge (Mitutoyo, Co., Tokyo, Japan).

On day 28, blood samples were collected by orbital puncture. After the blood had clotted at room temperature, it was centrifuged at $400 \mathrm{x} \mathrm{g}$ for $15 \mathrm{~min}$ at $4^{\circ} \mathrm{C}$, and the serum was isolated. The serum was stored at $-80^{\circ} \mathrm{C}$ for additional analysis. The ear of each mice was removed and subjected to histopathological analysis. Serum IgE and IgG2a levels were measured using an enzyme-linked immunosorbent assay (ELISA) kit (BD Biosciences, Oxford, UK) according to the manufacturer's instructions. For the detection of DFE-specific IgE, 96-well plates (Nunc, Wiesbaden, Germany) were coated with $10 \mathrm{mg}$ DFE in PBS. The DFE-specific IgE level was indicated by the OD value.

Histological observation. The ears were fixed with $10 \%$ formaldehyde and embedded in paraffin. Sections $(5 \mu \mathrm{m})$ were stained with hematoxylin and eosin (H\&E) and toluidine blue (TB). To measure Infiltrated lymphocytes, thickening of the epidermis, and fibrosis in the dermis, skin sections were stained with H\&E and the stained fields were observed by microscopy. To measure mast cell infiltration, skin sections were stained with TB, and the number of mast cells in the 5 sites chosen at random was counted. Eosinophils were counted in a blinded manner in 10 high-power fields at a magnification of $x 400$. Epidermal and dermal thickness of the H\&E-stained sections was analyzed under a magnification of $\mathrm{x} 200$. Thickness was measured in 5 randomly chosen fields from each sample.

Histamine assay. Histamine content was measured following the o-phthaldialdehyde spectrofluorometric procedure of a previous study (25). The blood from mice was centrifuged at $400 \mathrm{x} g$ for $15 \mathrm{~min}$, and the serum was diluted with PBS and withdrawn to measure the histamine content. Fluorescence intensity was measured using 355-nm excitation and 450-nm filters and the fluorescence spectrometer LS-50B (PerkinElmer, Norwalk, CT, USA).

$q P C R$. To detect the expression of cytokines, qPCR was performed using the Thermal Cycler Dice TP850 (Takarabio Inc., Shiga, Japan) according to the manufacturer's protocol. HaCaT cells $\left(1 \times 10^{5}\right.$ cells/24-well plate) were pretreated with AEDKC for $1 \mathrm{~h}$, and then stimulated with TNF- $\alpha(10 \mathrm{ng} / \mathrm{ml})$ and IFN- $\gamma(10 \mathrm{ng} / \mathrm{ml})$ for $6 \mathrm{~h}$. Total cellular 

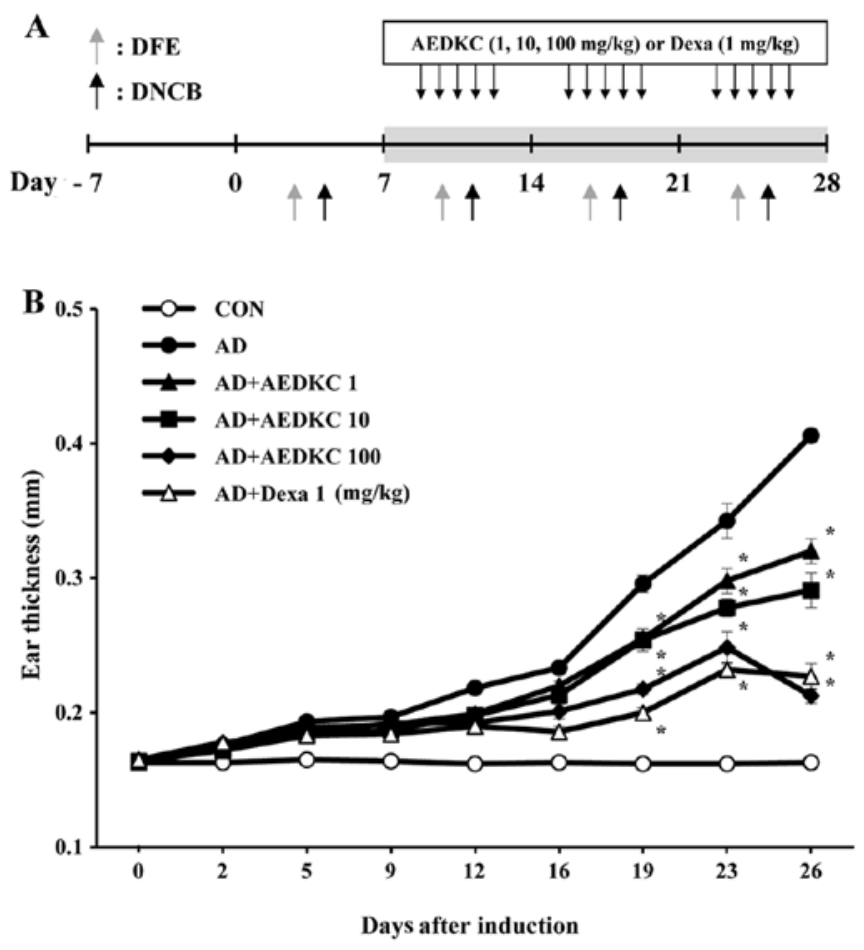

Figure 1. Experimental design and ear thickness of mice. (A) Experimental design of the induction of atopic dermatitis (AD). One week after the first exposure to Dermatophagoides farinae extract (DFE) (10 mg/ml, $20 \mu \mathrm{l} / \mathrm{ear}$, $1 \%$ 2,4-dinitrochlorobenzene (DNCB) $(20 \mu \mathrm{l} / \mathrm{ear})$ was rotationally applied to both ears once a week for 4 weeks. After 1 week of induction, an aqueous extract of $D$. kaki calyx (AEDKC) $(1,10$ or $100 \mathrm{mg} / \mathrm{kg}$ ) was orally administered every day for 3 weeks (n=5). (B) Ear thickness was measured $24 \mathrm{~h}$ after DFE or DNCB exposure with a dial thickness gauge. Data are presented as mean $\pm \mathrm{SE}(\mathrm{n}=5)$. " $\mathrm{p}<0.05$, significantly lower than those of AD mice. Dexa, dexamethasone.

RNA was isolated from cells as described in a previous study (4). Briefly, $1 \mu \mathrm{l}$ of cDNA (100 ng), $1 \mu \mathrm{l}$ of a sense and antisense primer solution $(0.4 \mu \mathrm{M}), 12.5 \mu \mathrm{l}$ of SYBR Premix Ex Taq (Takarabio Inc), and $9.5 \mu \mathrm{l}$ of nuclease-free water were mixed together to obtain a final $25 \mu \mathrm{l}$ reaction mixture in each reaction tube. The conditions for PCR were similar to those of a previous study (4). The normalization and quantification of mRNA expression were performed using TP850 software supplied by the manufacturer.

Western blot analysis. Samples for western blot analysis were prepared in accordance with a previous study (26). Briefly, HaCaT cells $\left(2 \times 10^{6}\right.$ cells/6-well plate) were pretreated with AEDKC for $1 \mathrm{~h}$ and then stimulated with TNF- $\alpha$ (10 ng/ $\mathrm{ml})$ and IFN- $\gamma(10 \mathrm{ng} / \mathrm{ml})$ for $30 \mathrm{~min}$ to activate signal transducer and activator of transcription 1 (STAT1) and nuclear factor- $\kappa \mathrm{B}(\mathrm{NF}-\kappa \mathrm{B})$. Cells were rinsed once with ice-cold PBS, and total cell lysates were collected in $100 \mu \mathrm{l}$ of lysis buffer. The lysates were spun in a micro-centrifuge for $20 \mathrm{~min}$ at $4^{\circ} \mathrm{C}$, and the supernatant was collected. Proteins were subjected to $10 \%$ sodium dodecyl sulfate-polyacrylamide gel electrophoresis (SDS-PAGE) and then transferred to nitrocellulose membranes. The membranes were stained with reversible Ponceau $\mathrm{S}$ to ensure equal loading of samples onto the gels.

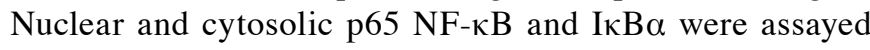

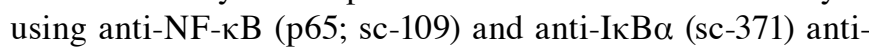
bodies (Santa Cruz Biotechnology, Inc., Santa Cruz, CA,
USA), respectively. The phosphorylation of STAT1 was detected using anti-STAT1 (\#9172) and anti-phospho-STAT1 (\#9167) antibodies (Cell Signaling Technology, Beverly, MA, USA). Anti- $\beta$-actin (sc-8432; mouse monoclonal; 1:1,000) was from Santa Cruz Biotechnology, Inc. Immunodetection was conducted using Supersignal West Pico Chemiluminescent Substrate (Thermo Fisher Scientific, Waltham, MA, USA).

Statistical analysis. Statistical analyses were performed using Prism 5 (GraphPad Software, San Diego, CA, USA). Treatment effects were analyzed using one-way analysis of variance followed by Dunnett's test. A p-value $<0.05$ indicates a statistically significant difference.

\section{Results}

Effects of AEDKC on histopathological observations. To investigate the efficacy of AEDKC on AD-like skin lesions, a DFE/DNCB-induced AD-like model was used. During the induction period, the ear swelling of mice was measured after $24 \mathrm{~h}$ of DFE or DNCB induction (Fig. 1B). The tendency of ear swelling of mice in each group was similar until after 2 weeks. After 19 days of AD induction, oral administration of AEDKC considerably reduced ear thickness. DFE/DNCB treatment during the induction period (4 weeks) evoked severe AD-like skin lesions (Fig. 2A). Mouse ears became red and swollen after DFE/DNCB exposure. However, oral treatment of AEDKC relieved these symptoms compare to the AD mice. Dexamethasone (Dexa) was used as a positive control drug. Oral administration of AEDKC five consecutive days a week during 3 weeks did not alter the body weight of mice (data not shown), indicating that AEDKC exhibited no toxic effects.

Histological analysis showed that AEDKC treatment significantly suppressed erythema and infiltration of acute inflammatory cells compared with the AD mice (Fig. 2B-D). Epidermis thickening is regarded as an important factor that contributes to ear swelling (22). Compared to the AD mice, AEDKC considerably decreased DFE/DNCB-induced epidermal and dermal thickness (Fig. 2B) and infiltration of eosinophils (Fig. 2C). Mast cell-derived inflammatory mediators and histamine contribute to itching and inflammation in $\mathrm{AD}$ (7). Thus, mast cell infiltration into the AD site and serum histamine level were measured; AEDKC attenuated both mast cell infiltration (Fig. 2D) and serum histamine (Fig. 3A).

Effects of AEDKC on serum immunoglobulin. We previously reported a substantial increase in serum immunoglobulin and cytokines in DFE/DNCB-induced AD mice (4). To distinguish the role of AEDKC on the Th1 and Th2 response, we examined individually the serum levels of IgG2a and IgE (total and DFE-specific). Compared with the AD mice, the levels of total IgE, DFE-specific IgE, and IgG2a were markedly decreased in the serum of mice treated with AEDKC (Fig. 3B-D).

Effects of AEDKC on keratinocyte activation. After establishing the inhibitory effect of AEDKC on AD mice, the keratinocyte model was used to ascertain the molecular mechanism and biological function of AEDKC. Keratinocytes have been broadly used to imitate the AD environment in vitro (27). They exhibit a similar immune response during 


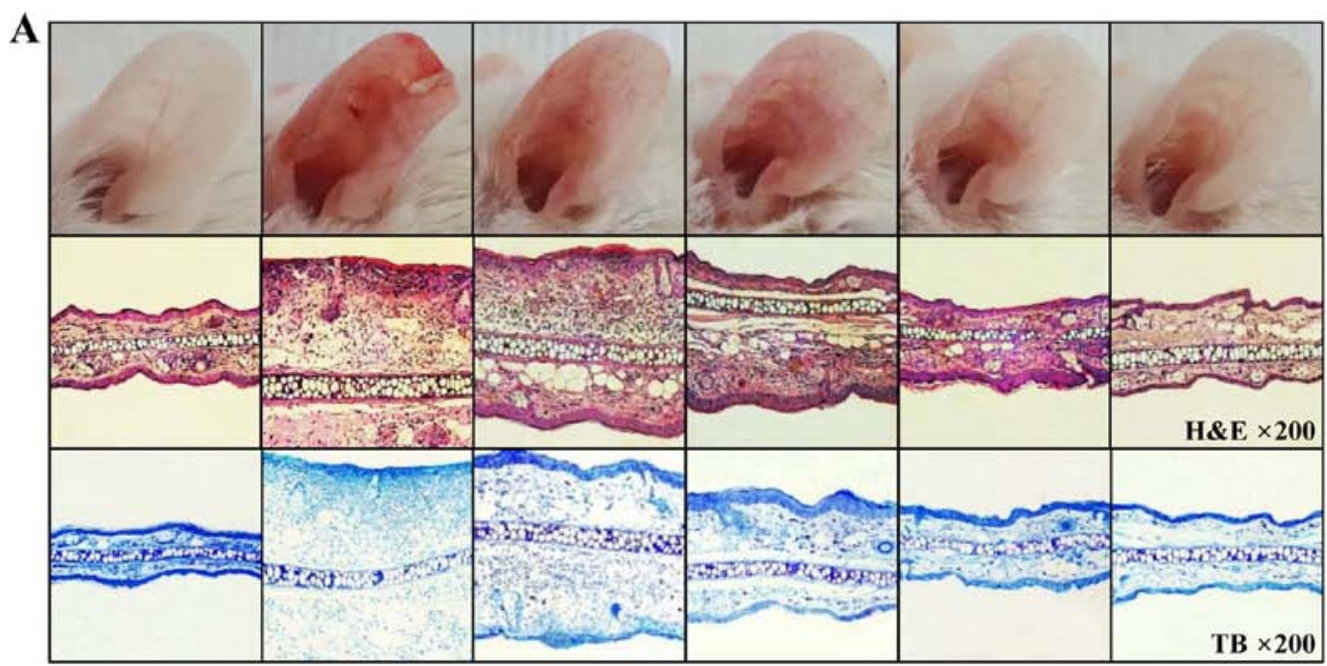

CON AD

AD+AEDKC 1 AD+AEDKC 10 AD+AEDKC 100

AD+Dexa $1(\mathrm{mg} / \mathrm{kg})$
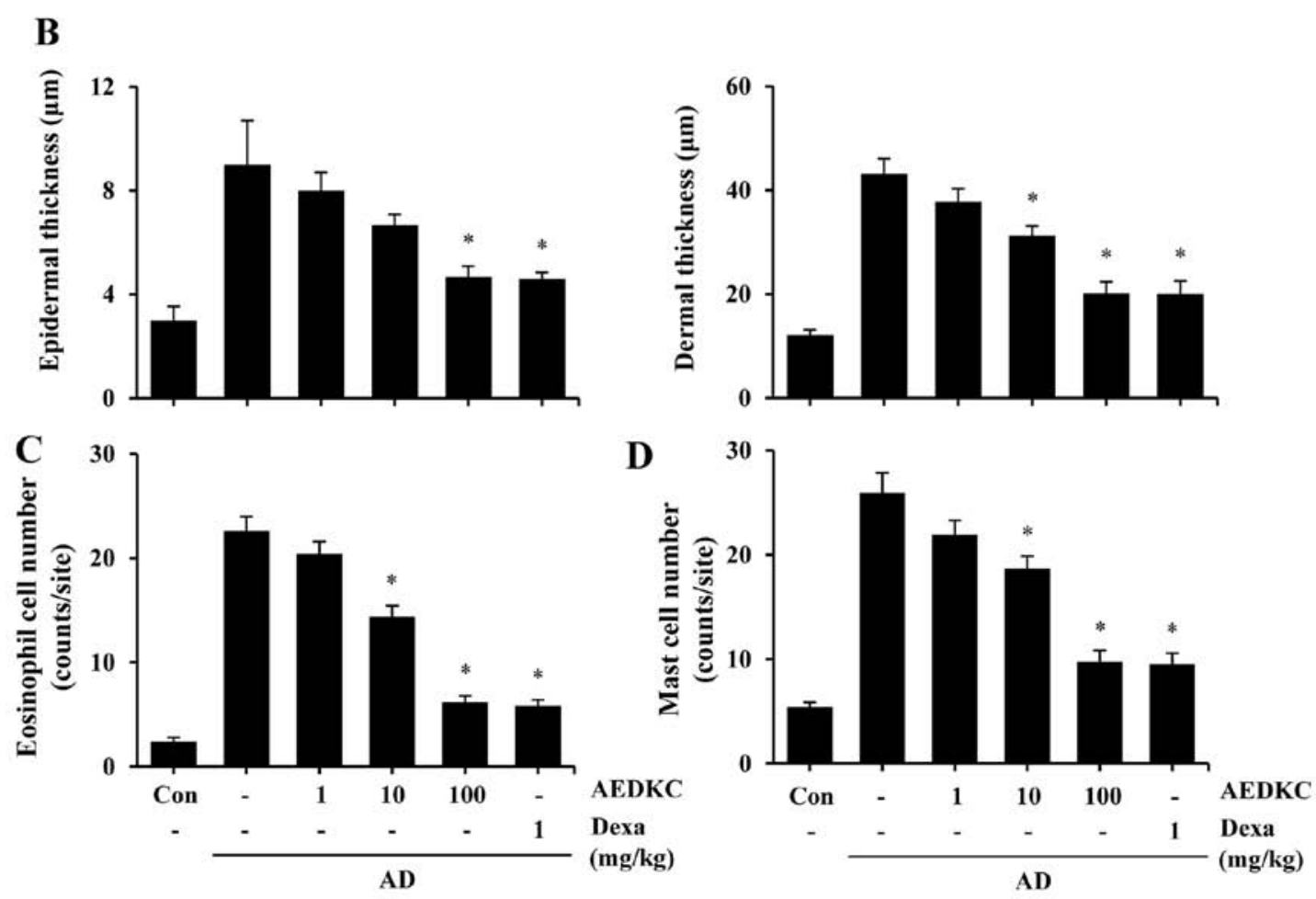

Figure 2. Representative images of the effects of an aqueous extract of D. kaki calyx (AEDKC) on Dermatophagoides farinae extract (DFE)/2,4dinitrochlorobenzene (DNCB)-induced atopic dermatitis (AD)-like skin lesions in the ear, histological analysis, and cell infiltration in mice. (A) Representative photomicrographs (upper panel) of ear sections stained with hematoxylin and eosin (H\&E, middle panel) or toluidine blue (TB, lower panel). (B) Epidermal and dermal thickness $(\mu \mathrm{m})$. (C and D) The number of cells is expressed as the mean number of cells at 5 random sites for each animal. Data are presented as mean $\pm \mathrm{SE}(\mathrm{n}=5)$. ${ }^{\mathrm{p}}<0.05$, significantly lower than those of the AD mice. Dexa, dexamethasone.

the development of skin disorders, such as AD-like skin lesions (28). First, we evaluated the cytotoxicity of AEDKC by exposing $\mathrm{HaCaT}$ cells to various concentrations of AEDKC for $24 \mathrm{~h}$. In the MTT assay, AEDKC did not exert cytotoxicity at concentrations up to $1,000 \mu \mathrm{g} / \mathrm{ml}$ in the keratinocytes (data not shown). To examine the effect of AEDKC on proinflammatory cytokines and a chemokine, HaCaT cells were pretreated with AEDKC for $1 \mathrm{~h}$, followed by the stimulation with TNF- $\alpha / \mathrm{IFN}-\gamma$ for $6 \mathrm{~h}$. The results of qPCR indicated that AEDKC inhibited TNF- $\alpha /$ IFN- $\gamma$-induced gene expression of TNF- $\alpha$, IL-1 $\beta$, IL-6 and CCL17 in the HaCaT cells (Fig. 4).
Thereafter, the regulatory effect of AEDKC on the expression of pro-inflammatory cytokines and a chemokine was examined. To establish the mechanism responsible for the inhibitory effect of AEDKC, we investigated the effect of AEDKC on TNF- $\alpha /$ IFN- $\gamma$-induced activation of STAT1 and NF- $\kappa$ B. Previous studies have reported that the STAT and NF- $\kappa \mathrm{B}$ signaling pathways contribute to the production of pro-inflammatory cytokines (TNF- $\alpha$, IL-1 $\beta$ and IL-6) and chemokine (CCL17) in TNF- $\alpha / \mathrm{IFN}-\gamma$-induced $\mathrm{HaCaT}$ cells $(29,30)$. As shown in Fig. 5, activation of STAT1 and NF- $\kappa B$ was reduced by AEDKC $(1,000 \mu \mathrm{g} / \mathrm{ml})$. 

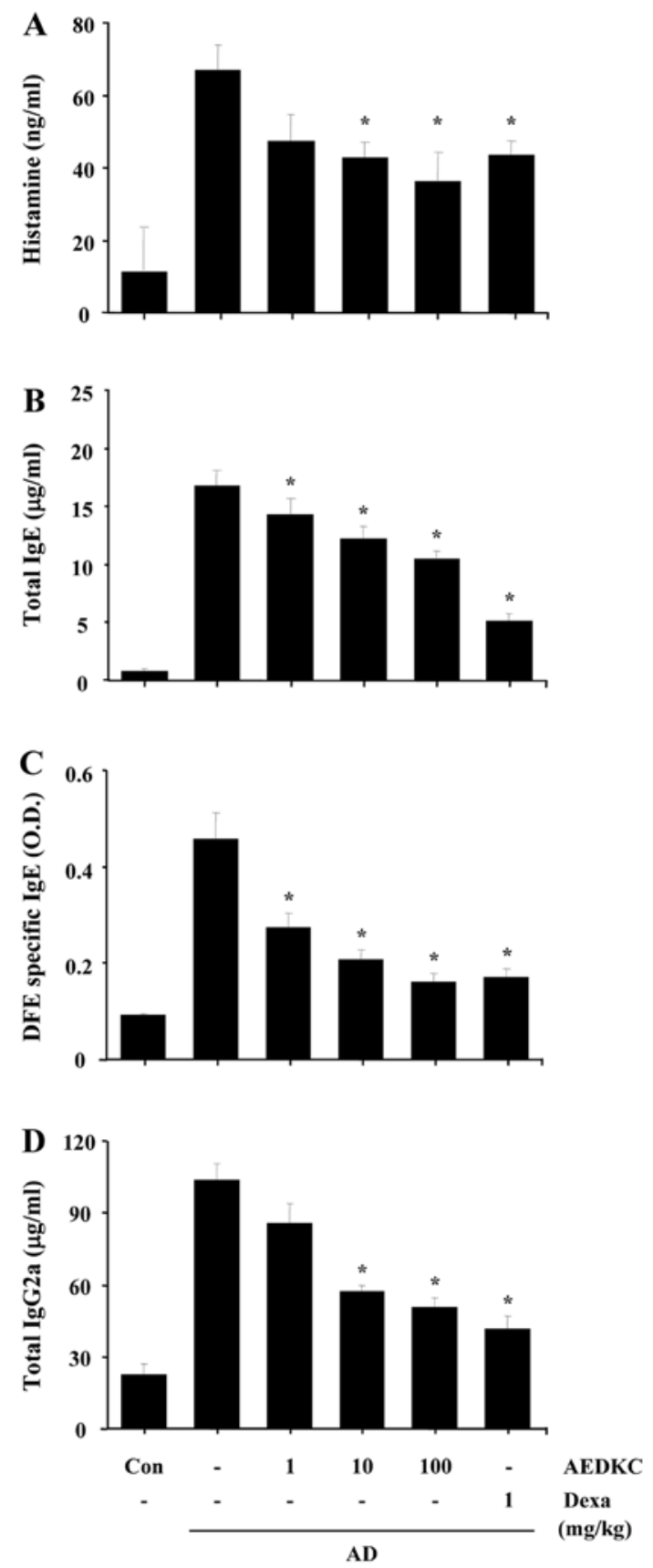

Figure 3. Serum levels of histamine and immunoglobulin E (IgE) in mice. The blood samples were collected by orbital puncture after 28 days. (A) Histamine levels were detected using a fluorescent plate reader (B) Serum total IgE levels, (C) Dermatophagoides farinae extract (DFE)specific IgE levels, and (D) total IgG2a levels were measured by ELISA. Data are presented as mean $\pm S E(n=5)$. " $p<0.05$, significantly lower than those in atopic dermatitis (AD) mice. Dexa, dexamethasone.

\section{Discussion}

Various parts of Diospyros kaki have been widely used as a herbal medicine including the treatment of allergic inflammation (17,31). D. kaki folium ameliorates transepidermal water loss in AD and allergic skin symptoms (32). D. kaki calyx has been generally used to relieve asthma, cough symptoms and chronic bronchitis $(19,20)$. Various ingredients of $D$. kaki calyx have been reported (39). Among them, gallic acid, oleanolic acid, quercetin, and $\beta$-sitosterol are known to act as biological
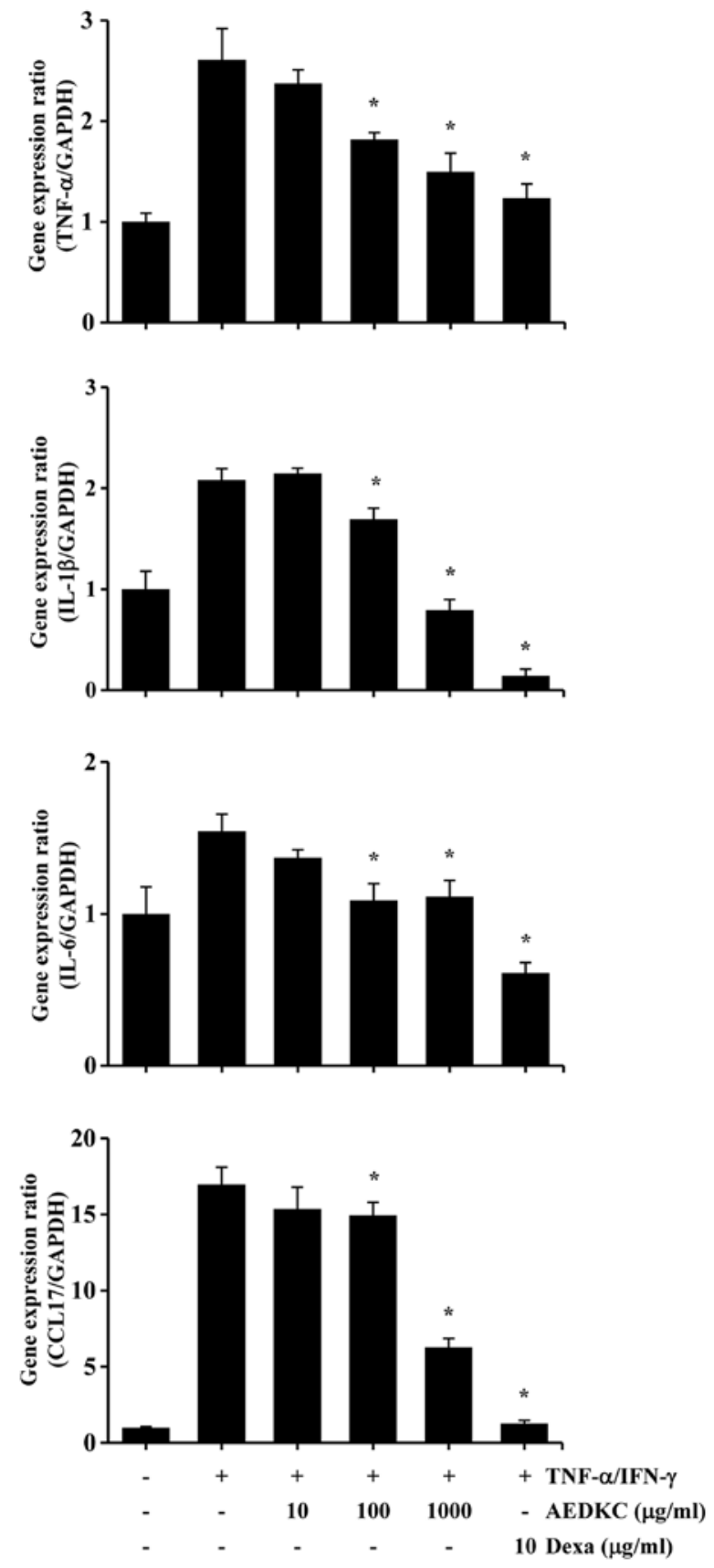

Figure 4. Expression of cytokines and chemokine in tumor necrosis factor- $\alpha$ (TNF- $\alpha) /$ interferon- $\gamma($ IFN- $\gamma)$-stimulated HaCaT cells. Cells were pretreated with an aqueous extract of $D$. kaki calyx (AEDKC) $(10,100$ and $1,000 \mu \mathrm{g} / \mathrm{ml})$ or Dexa $(10 \mu \mathrm{g} / \mathrm{ml})$ for $1 \mathrm{~h}$ and then stimulated with TNF- $\alpha$ $(10 \mathrm{ng} / \mathrm{ml})$ and IFN- $\gamma(10 \mathrm{ng} / \mathrm{ml})$ for $6 \mathrm{~h}$. The expression levels of cytokines and chemokine CCL17 were determined by qPCR. Data are presented as mean \pm SE. ${ }^{*} p<0.05$, significantly lower than the TNF- $\alpha /$ IFN- $\gamma$-stimulated positive control. Dexa, dexamethasone.

active compounds (4,22-24). Based on the known various pharmacological activity of $D$. kaki, the role of AEDKC on AD-like skin lesions was evaluated using in vivo and in vitro models.

To examine the effect of AEDKC on AD-like skin lesions, we adopted a DFE/DNCB-induced AD mouse model. This $\mathrm{AD}$ model is often used by many researchers due to the reproducibility and AD-like characteristics involved in both Th1 and Th2 responses as in human AD patients exposed to DFE, a common allergen $(1,4,9)$. We previously reported 


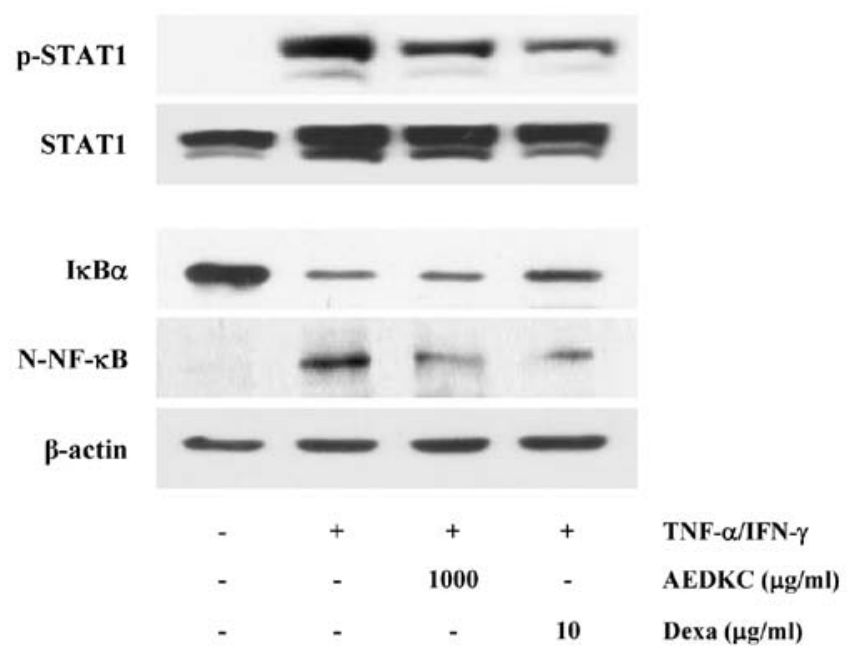

Figure 5. Effect of an aqueous extract of D. kaki calyx (AEDKC) on signal transducer and activator of transcription 1 (STAT1) and nuclear factor- $\kappa \mathrm{B}$ (NF- $\kappa \mathrm{B})$ signaling pathways. Cells were pretreated with AEDKC $(1,000 \mu \mathrm{g} /$ $\mathrm{ml})$ or Dexa $(10 \mu \mathrm{g} / \mathrm{ml})$ for $1 \mathrm{~h}$ and then stimulated with tumor necrosis factor- $\alpha(\mathrm{TNF}-\alpha)(10 \mathrm{ng} / \mathrm{ml})$ and interferon- $\gamma(\mathrm{IFN}-\gamma)(10 \mathrm{ng} / \mathrm{ml})$ for $30 \mathrm{~min}$ for the activation of STAT1 and NF- $\mathrm{NB}$. The phosphorylation of STAT1, degradation of $\mathrm{I} \kappa \mathrm{B} \alpha$, and nuclear translocation of NF- $\kappa \mathrm{B}$ were analyzed by western blot analysis. The data shown represent three independent experi-

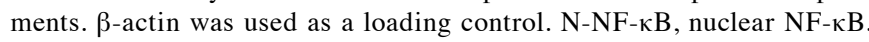
Dexa, dexamethasone.

that this mouse model exhibits phenotypes reminiscent of both acute and chronic AD lesions, including spongiosis, epidermal hyperplasia, fibrosis and infiltration of inflammatory cells (eosinophils and mast cells) (4). In the present study, we confirmed that mice epicutaneously sensitized with DFE/DNCB exhibited ear redness and swelling, hyperplasia and dysregulated differentiation of the epidermis, and infiltration of dermal inflammatory cells. Oral administration of AEDKC relieved the typical and histological changes such as intense ear thickness, dysregulated differentiation of the epidermis, dermal and epidermal thickness, epidermal hyperplasia, and infiltration of inflammatory cells. Mast cells are key effector cells in patients with $\operatorname{IgE}$ receptor (FceRI)bearing immediate allergic disorders (33). Activation of mast cells leads to the release of mediators such as cytokines and histamine. Histamine mainly induces pruritus and edema; thus, it is likely to be a crucial mediator in AD patients (34). In addition, serum histamine levels have been reported to be significantly higher in AD patients than that in normal human skin (35). The present results indicate that oral administration of AEDKC reduced serum histamine levels and the pathogenesis of skin lesions in AD.

In $\mathrm{AD}$ condition, keratinocytes release a characteristic form of cytokines/chemokines after pro-inflammatory cytokine exposure (36). TNF- $\alpha$ and IFN- $\gamma$ can synergistically induce important cytokines for AD symptoms in keratinocytes, and this experimental model has been widely used to mimic the AD environment in vitro $(4,27)$. Several studies have reported that CCL17 is overexpressed in the serum of AD patients, and that the severity of AD is strongly correlated with the chemokine levels $(37,38)$. Dexamethasone is an effective immunosuppressive medication widely used in the treatment of AD (39). Thus, it was used as a positive control. The present results indicated that AEDKC treatment suppressed TNF- $\alpha$ / IFN- $\gamma$-induced TNF- $\alpha$, IL-1 $\beta$, IL-6 and CCL17. Compared to the effects of dexamethasone, AEDKC at a high dose showed a similar immune suppressive effect in keratinocytes.

STAT1 and NF- $\kappa$ B in the cytoplasm translocate into the nucleus, where they participate in the expression of proinflammatory genes (30). CCL17 promoters contain STAT1 and $\mathrm{NF}-\kappa \mathrm{B}$ binding sequences, and these transcription factors mediate the transcription of genes (30). In this study, we demonstrated that AEDKC inhibited the signaling pathways involved in the activation of STAT1 and NF- $\mathrm{B}$. AEDKC suppressed STAT1 phosphorylation. Furthermore, AEDKC inhibited the degradation of $\mathrm{I} \kappa \mathrm{B} \alpha$ and nuclear translocation of NF- $\kappa \mathrm{B}$. These results indicate that AEDKC exerts inhibitory effect on CCL17 via the downregulation of both STAT1 and NF- $\kappa$ B. This study provides evidence that AEDKC has suppressive effects on TNF- $\alpha / \mathrm{IFN}-\gamma$-induced expression of pro-inflammatory cytokines and chemokine by the blocking of STAT1 and NF- $\mathrm{BB}$. CCL17 is adjusted by the STAT1 and $\mathrm{NF}-\kappa \mathrm{B}$ pathways in keratinocytes; thus, the present results indicate that $\mathrm{AEDKC}$ may reduce AD-like skin lesions by suppressing CCL17.

In this study, we demonstrated that AEDKC suppressed the development of AD-like skin lesions in both in vivo and in vitro models. AEDKC inhibited the cytokines and chemokine involved in AD via blocking NF- $\kappa$ B and STAT1 signaling pathways in keratinocytes. Taken together, AEDKC is a potential effective treatment for AD and could be used as a pharmacological agent or food supplement.

\section{Acknowledgements}

This study was supported by the National Research Foundation of Korea (nos. 2014R1A5A2009242, 2012M3A9B6055416 and 2016R1A2B4008513), KRIBB Research Initiative Program (KGM4251723), and High Value-added Food Technology Development Program, Ministry of Agriculture, Food and Rural Affairs.

\section{References}

1. Bieber T: Atopic dermatitis. Ann Dermatol 22: 125-137, 2010.

2. Boguniewicz M and Leung DY: Atopic dermatitis: A disease of altered skin barrier and immune dysregulation. Immunol Rev 242: 233-246, 2011.

3. Dai X, Sayama K, Tohyama M, Shirakata Y, Hanakawa Y, Tokumaru S, Yang L, Hirakawa S and Hashimoto K: Mite allergen is a danger signal for the skin via activation of inflammasome in keratinocytes. J Allergy Clin Immunol 127: 806-14.e1, 4, 2011.

4. Choi JK, Oh HM, Lee S, Park JW, Khang D, Lee SW, Lee WS, Rho MC and Kim SH: Oleanolic acid acetate inhibits atopic dermatitis and allergic contact dermatitis in a murine model. Toxicol Appl Pharmacol 269: 72-80, 2013.

5. Kwon HK, Lee CG, So JS, Chae CS, Hwang JS, Sahoo A, Nam JH, Rhee JH, Hwang KC and Im SH: Generation of regulatory dendritic cells and $\mathrm{CD} 4^{+} \mathrm{Foxp}^{+} \mathrm{T}$ cells by probiotics administration suppresses immune disorders. Proc Natl Acad Sci USA 107: 2159-2164, 2010.

6. Kim JY, Jeong MS, Park MK, Lee MK and Seo SJ: Time-dependent progression from the acute to chronic phases in atopic dermatitis induced by epicutaneous allergen stimulation in NC/Nga mice. Exp Dermatol 23: 53-57, 2014.

7. Oyoshi MK, He R, Kumar L, Yoon J and Geha RS: Cellular and molecular mechanisms in atopic dermatitis. Adv Immunol 102: 135-226, 2009. 
8. Matsushima H, Hayashi S and Shimada S: Skin scratching switches immune responses from Th2 to Th1 type in epicutaneously immunized mice. J Dermatol Sci 32: 223-230, 2003.

9. Novak N: New insights into the mechanism and management of allergic diseases: Atopic dermatitis. Allergy 64: 265-275, 2009.

10. Yoon SY, Kang HB, Ko YE, Shin SH, Kim YJ, Sohn KY, Han YH, Chong S and Kim JW: 1-palmitoyl-2-linoleoyl-3-acetyl-racglycerol (EC-18) Modulates Th2 Immunity through Attenuation of IL-4 Expression. Immune Netw 15: 100-109, 2015.

11. Kaiko GE and Foster PS: New insights into the generation of Th2 immunity and potential therapeutic targets for the treatment of asthma. Curr Opin Allergy Clin Immunol 11: 39-45, 2011.

12. Girolomoni $\mathrm{G}$ and Pastore S: Epithelial cells and atopic diseases. Curr Allergy Asthma Rep 1: 481-482, 2001.

13. Trautmann A, Akdis M, Schmid-Grendelmeier P, Disch R, Bröcker EB, Blaser K and Akdis CA: Targeting keratinocyte apoptosis in the treatment of atopic dermatitis and allergic contact dermatitis. J Allergy Clin Immunol 108: 839-846, 2001.

14. Wollenberg A and Ehmann LM: Long term treatment concepts and proactive therapy for atopic eczema. Ann Dermatol 24 253-260, 2012.

15. Hsu CJ and Wang LF: Emerging treatment of atopic dermatitis Clin Rev Allergy Immunol 33: 199-203, 2007.

16. Choi JH, Jin SW, Park BH, Kim HG, Khanal T, Han HJ, Hwang YP, Choi JM, Chung YC, Hwang SK, et al: Cultivated ginseng inhibits 2,4-dinitrochlorobenzene-induced atopic dermatitis-like skin lesions in NC/Nga mice and TNF- $\alpha /$ IFN- $\gamma$-induced TARC activation in HaCaT cells. Food Chem Toxicol 56: 195-203, 2013.

17. Kim HH, Kim DS, Kim SW, Lim SH, Kim DK, Shin TY and Kim SH: Inhibitory effects of Diospyros kaki in a model of allergic inflammation: Role of cAMP, calcium and nuclear factor- $\kappa$ B. Int J Mol Med 32: 945-951, 2013.

18. Jung HG, Kim HH, Paul S, Jang JY, Cho YH, Kim HJ, Yu JM, Lee ES, An BJ, Kang SC, et al: Quercetin-3-O- $\beta$-dglucopyranosyl-( $1 \rightarrow 6)-\beta$-d-glucopyranoside suppresses melanin synthesis by augmenting p38 MAPK and CREB signaling pathways and subsequent cAMP downregulation in murine melanoma cells. Saudi J Biol Sci 22: 706-713, 2015.

19. Bei W, Zang L, Guo J, Peng W, Xu A, Good DA, Hu Y, Wu W, Hu D, Zhu X, et al: Neuroprotective effects of a standardized flavonoid extract from Diospyros kaki leaves. J Ethnopharmacol 126: 134-142, 2009.

20. Sa YS, Kim SJ and Choi HS: The anticoagulant fraction from the leaves of Diospyros kaki L. has an antithrombotic activity. Arch Pharm Res 28: 667-674, 2005.

21. Singh S and Joshi h: Diospyros kaki (Ebenaceae): A Review. Asian J Res Pharm Sci 1: 55-58, 2011

22. Tsang MS, Jiao D, Chan BC, Hon KL, Leung PC, Lau CB, Wong EC, Cheng L, Chan CK, Lam CW, et al: Anti-inflammatory activities of pentaherbs formula, berberine, gallic acid and chlorogenic acid in atopic dermatitis-like skin inflammation. Molecules 21: 519, 2016.

23. Karuppagounder V, Arumugam S, Thandavarayan RA, Sreedhar R, Giridharan VV and Watanabe K: Molecular targets of quercetin with anti-inflammatory properties in atopic dermatitis. Drug Discov Today 21: 632-639, 2016.

24. Han NR, Kim HM and Jeong HJ: The $\beta$-sitosterol attenuates atopic dermatitis-like skin lesions through downregulation of TSLP. Exp Biol Med (Maywood) 239: 454-464, 2014.

25. Bae Y, Lee S and Kim SH: Chrysin suppresses mast cell-mediated allergic inflammation: Involvement of calcium, caspase-1 and nuclear factor- $\kappa$ B. Toxicol Appl Pharmacol 254: 56-64, 2011
26. Lee S, Yun HS and Kim SH: The comparative effects of mesoporous silica nanoparticles and colloidal silica on inflammation and apoptosis. Biomaterials 32: 9434-9443, 2011.

27. Leung DYM, Boguniewicz M, Howell MD, Nomura I and Hamid QA: New insights into atopic dermatitis. J Clin Invest 113: 651-657, 2004.

28. Guttman-Yassky E, Nograles KE and Krueger JG: Contrasting pathogenesis of atopic dermatitis and psoriasis - part I: Clinical and pathologic concepts. J Allergy Clin Immunol 127: 1110-1118, 2011.

29. Kim SY, Sohn EJ, Kim DW, Jeong HJ, Kim MJ, Kang HW, Shin MJ, Ahn EH, Kwon SW, Kim YN, et al: Transduced PEP-1-FK506BP ameliorates atopic dermatitis in NC/Nga mice. J Invest Dermatol 131: 1477-1485, 2011.

30. Kwon DJ, Bae YS, Ju SM, Goh AR, Youn GS, Choi SY and Park J: Casuarinin suppresses TARC/CCL17 and MDC/CCL22 production via blockade of NF- $\kappa$ B and STAT1 activation in HaCaT cells. Biochem Biophys Res Commun 417: 1254-1259, 2012.

31. Xie C, Xie Z, Xu X and Yang D: Persimmon (Diospyros kaki L.) leaves: A review on traditional uses, phytochemistry and pharmacological properties. J Ethnopharmacol 163: 229-240, 2015.

32. Matsumoto M, Kotani M, Fujita A, Higa S, Kishimoto T, Suemura $\mathrm{M}$ and Tanaka T: Oral administration of persimmon leaf extract ameliorates skin symptoms and transepidermal water loss in atopic dermatitis model mice, $\mathrm{NC} / \mathrm{Nga}$. Br J Dermatol 146: 221-227, 2002.

33. Oka T, Rios EJ, Tsai M, Kalesnikoff J and Galli SJ: Rapid desensitization induces internalization of antigen-specific $\operatorname{IgE}$ on mouse mast cells. J Allergy Clin Immunol 132: 922-32.e1-16, 2013.

34. Kawakami T, Ando T, Kimura M, Wilson BS and Kawakami Y: Mast cells in atopic dermatitis. Curr Opin Immunol 21: 666-678, 2009.

35. Greaves MW: Antihistamines in dermatology. Skin Pharmacol Physiol 18: 220-229, 2005.

36. Akdis CA, Akdis M, Bieber T, Bindslev-Jensen C, Boguniewicz M, Eigenmann P, Hamid Q, Kapp A, Leung DY, Lipozencic J, et al: Diagnosis and treatment of atopic dermatitis in children and adults: European Academy of Allergology and Clinical Immunology/American Academy of Allergy, Asthma and Immunology/PRACTALL Consensus Report. J Allergy Clin Immunol 118: 152-169, 2006.

37. Shimada Y, Takehara K and Sato S: Both Th2 and Th1 chemokines (TARC/CCL17, MDC/CCL22, and Mig/CXCL9) are elevated in sera from patients with atopic dermatitis. J Dermatol Sci 34: 201-208, 2004

38. Jahnz-Rozyk K, Targowski T, Paluchowska E, Owczarek W and Kucharczyk A: Serum thymus and activation-regulated chemokine, macrophage-derived chemokine and eotaxin as markers of severity of atopic dermatitis. Allergy 60: 685-688, 2005.

39. Schmitt J, von Kobyletzki L, Svensson A and Apfelbacher C: Efficacy and tolerability of proactive treatment with topical corticosteroids and calcineurin inhibitors for atopic eczema: Systematic review and meta-analysis of randomized controlled trials. Br J Dermatol 164: 415-428, 2011. 